\title{
Prevalence of Anemia and Its Associated Factors Among Pregnant Women Attending Antenatal Clinic At SOS Hospital In Heliwa District, Mogadishu
}

\author{
Hassan Abdullahi Dahie \\ Faculty of Health Science \\ Mustaqbal University, Mogadishu-Somalia \\ SOS Community Nursing School, Mogadishu-Somalia. \\ Abdullahi Ali Heyle \\ SOS Community Nursing School \\ Mogadishu-Somalia
}

\begin{abstract}
Background: Anaemia in pregnancy is a common problem in most developing countries and a major cause of morbidity and mortality. In pregnancy, anaemia has a significant impact on the health of the foetus as well as that of the mother. $20 \%$ of maternal deaths in Africa have been attributed to anaemia. Objective: To assess the prevalence of anemia and its associated factors among pregnant women attending antenatal clinic at SOS Hospital, Heliwa District, in Mogadishu, Somalia 2016. Methodology: Facility based cross-sectional study was conducted at SOS Hospital Heliwa District, in Mogadishu, Somalia 2016, from September to December 2016. Data were collected using pretested questionnaires. A total of $\mathbf{4 0 3}$ pregnant women were included in the study. Data were entered and analyzed using STATA version 12. Both Univariate and Bivariate analysis were carried out to see frequencies and significant associations, a P-value less than 0.05 was considered as significant association. Result: In the study the prevalence of anaemia was 84.3 per cent among pregnant women ( 340 out of 403 ). Out of 340 , 61(15.14 \%) had mild anaemia (hb10 to $10.99 \mathrm{gm} / \mathrm{dl}), 228(56.5 \%)$ had moderate anaemia (hb 7 to $9.9 \mathrm{gm} / \mathrm{dl})$ and $51(12.7 \%)$ had severe anaemia $(\mathrm{hb}<7 \mathrm{gm} / \mathrm{dl})$. The study has shown that age of the pregnant women and family size were found to be significant. Pregnant women at age of 25--29 were less likely to be anemic compared to those pregnant women at the age of $20-24$ (OR 0.75, 95\%CI $0.37-0.87)$. Family size of pregnant women was found to be associated with anemia. Pregnant women whose family size $\geq 13$ were more likely to be anaemic compared to those whose family size was less than $\leq 12$ (OR 8.41, 95\%CI 1.33-52.92). Conclusion and Recommendation: In this study the prevalence of anemia is $84.3 \%$ among pregnant women. Comparing the national prevalence of anemia in pregnancy $(45.5 \%)$ it is higher, needs high effort by other researchers. Sensitization of pregnant women by health providers to encourage early ANC visit and to continue supplements of iron and folate throughout pregnancy. Provision of health education on anemia and importance of visits at least four times during pregnancy and establishment of mobile clinics.
\end{abstract}

Key words: Anemia, prevalence of anemia, pregnant women, antenatal care, multigravidae, primigravidae.

\section{INTRODUCTION}

Anemia, defined as a decreased concentration of blood hemoglobin, is one of the most common nutritional deficiency diseases observed globally and affects more than a quarter of the world's population (WHO/CDC, 2008; Haidar, 2010). It is a major public health problem affecting all ages of the population with its highest prevalence among children under five years of age and 
pregnant women. ( Balarajan,etal. 2011; Salhan,etal, 2012). Globally, anemia affects 1.62 billion people (25\%), among which 56 million are pregnant women (WHO/CDC,2008; Balarajan,etal. 2011).

Anemia during pregnancy is considered severe when hemoglobin concentration is less than $7.0 \mathrm{~g} / \mathrm{dL}$, moderate when hemoglobin falls between $7.0-9.9 \mathrm{~g} / \mathrm{dL}$, and mild from $10.0-11 \mathrm{~g} / \mathrm{dL}$ (Balarajan,etal. 2011 and Esma, et al, 2010). Anemia during pregnancy is a major cause of morbidity and mortality of pregnant women in developing countries and has both maternal and fetal consequences (Akhtar and Hassan, 2012 and Brooker, et al., 2008).

It is estimated that anemia causes more than 115,000 maternal and 591,000 perinatal deaths globally per year (Salhan,etal, 2012).

In developing countries, the cause of anemia during pregnancy is multifactorial and includes nutritional deficiencies of iron, folate, and vitamin B12 and also parasitic diseases, such as malaria. The relative contribution of each of these factors to anemia during pregnancy varies greatly by geographical location, season, and dietary practice. In Sub-Saharan Africa, iron and folate deficiencies are the most common causes of anemia in pregnant women (Baker and DeMaeyer, 1979).

Anemia has a variety of converging contributing factors including nutritional, genetic, and infectious disease factors; however, iron deficiency is the cause of $75 \%$ of anemia cases. (Balarajan,etal. 2011; Baig-Ansari, et al, 2008; Haidar,2010 and Toteja,et al, 2006).Iron deficiency anemia affects the development of the nation by decreasing the cognitive development of children and productivity of adults. Anemia in pregnancy is responsible for many adverse effects on maternal and fetal outcome. It is the commonest hematological disorder accompanying pregnancy. Prevalence of anemia among pregnant women is fairly high worldwide, especially in developing countries.

Somalia is one of the least developed countries in the world having low human development indexes: low literacy rate, low life expectancy and low GNI per capita (WHO, 1992). Moreover, women are even deprived of basic necessities which are essential to live a normal life. They are subjected to succumb easily to minor illness, especially, during pregnancy. Despite being a physiological condition, its outcome may be quite unpredictable. The success rate depends upon various factors such as associated morbid condition, number of previous pregnancies, prevailing health-care delivery system of the country, socio-economic status, literacy status, nature of occupations adopted by females, (Gautam VP, Bansal YY, Taneja DK, Saha R, 2002).

Anemia is one of the serious health problems among pregnant women in Somalia. A prevalence rate of anemia is believed to be higher in the general population, especially in pregnant women and in the children. Higher rates above $50 \%$ have also been reported in pregnant women (World Bank, 2004). The availability of local prevalence statistics has a major role in the management and control of anemia in pregnancy. However, it was not adequately done in the study area. Therefore, this study is aimed to assess the prevalence and associated risk factors of anemia among pregnant women attending at SOS Hospital in Heliwa District, Mogadishu.

\section{PROBLEM STATEMENT}

The importance of good haemoglobin concentration during pregnancy for both the woman and the growing foetus cannot be overemphasized. Being a driving force for oxygen for the mother and foetus, a reduction below acceptable levels can be detrimental to both (Agan, et al., 2010). 
To avoid low haemoglobin concentration (anemia), pregnant women take oral iron supplementation during antenatal care.

However, anaemia in pregnancy is a worldwide public health problem affecting both developing and developed countries with significant impact on the health of mothers and foetus (Siamak, 2014). Anaemia is an indicator of nutritional deficiencies that significantly contribute to birth defects, preterm labour and low birth weight, hence it causes global public health problem. However, iron deficiency anaemia is a leading cause of maternal morbidity and mortality, prenatal and perinatal infant loss; physical and cognitive losses thus in developing countries stall social and economic development. In sub-Saharan countries, including Somalia, the magnitude of anaemia in pregnancy is quite alarming, whereby its prevalence is widely contributed by poor nutrition, iron and other micronutrients deficiencies, parasitic infestations, chronic infections, illiteracy, and short pregnancy intervals (Agan, et al., 2010). According to the WHO classification, any prevalence level of anaemia that exceeds $40 \%$ in any population group is an indicator of a severe public health problem, for which Somalia qualifies. For example, a study conducted in two refugee camps in Somalia found that anaemia was the primary cause of maternal death and of the 44 deaths recorded, 42 had causes related to anaemia (Clegg and Weatherall 1999).

Consequently, if this condition continuous without been developed interventions of treating and preventing maternal anaemia many pregnant women will develop anemia that later causes birth defects, preterm labour and low birth weight, hence it causes national public health problem.

Therefore, the aim of the study on which this dissertation is based is to determine the prevalence of anaemia and its associated factors in pregnant women attending at SOS Hospital in Heliwa District.

\section{Broad objective}

\section{STUDY OBJECTIVES}

To determine the prevalence of anemia among pregnant women attending antenatal clinic at SOS hospital in Heliwa District.

\section{Specific objectives}

1. To determine the overall prevalence of anemia among women attending antenatal clinic at SOS Hospital

2. Assess the level of knowledge on anaemia among pregnant women towards control measures of anaemia in pregnancy attending at SOS Hospital in Heliwa District.

3. To assess associated factors of anemia among pregnant women attending antenatal care (ANC) at SOS Hospital in Heliwa district, Mogadishu.

\section{REVIEW OF RELATED LITERATURE}

Anemia is defined as a condition in which there is less than the normal hemoglobin (Hgb) level in the body, which decreases oxygen-carrying capacity of red blood cells to tissues. World Health Organization (WHO) definitions for anemia differ by age, sex and pregnancy status as follows: children 6 months to 5 year anemia is defined as a Hgb level $<11 \mathrm{~g} / \mathrm{dl}$, children $5-11$ years $\mathrm{Hgb}<11.5 \mathrm{~g} / \mathrm{dl}$, adult males $\mathrm{Hgb}<13 \mathrm{~g} / \mathrm{dl}$; nonpregnant women $\mathrm{Hgb}<12 \mathrm{~g} / \mathrm{dl}$ and pregnant women $\mathrm{Hgb}<11 \mathrm{~g} / \mathrm{dl}(\mathrm{WHO}, 2001)$. Anemia could be classified as mild, moderate and severe. The Hgb level for each class of anemia in pregnancy are 10.0-10.9g/d1 (mild), 79.9g/dl (moderate) and <7g/ dl (severe) (WHO, 1989). The Centers for Disease Control and Prevention (1990) defined anemia as hemoglobin $<11 \mathrm{~g} / \mathrm{dl}$ in the first and second trimesters 
and $<10.5 \mathrm{~g} / \mathrm{dl}$ in the third trimester. This is based on the reduction in hemoglobin level during pregnancy caused by the disproportion in volume expansion between the plasma and erythrocytes (WHO/CDC, 2008).

During a normal pregnancy, a woman's hematologic values change substantially (WHO, 2001). For women with adequate iron nutrition, $\mathrm{Hb}$ and Hct values start to decline during the early part of first trimester, reach their nadir near the end of second trimester, then gradually rise during the third trimester (WHO, 2001). Because of the change of $\mathrm{Hb}$ and Hct during pregnancy, anemia must be characterized according to the specific stage of pregnancy.

Anemia in pregnant women is often caused by iron deficiency, which is the most common nutrient deficiency in the world. It has been estimated that, in developing countries, half of the population (mainly children and women of reproductive age) is affected by anemia ( Hercberg and Galan, 1992). Anemia also could be caused due to increased hemolysis, diminished erythropoesis and blood loss (Sifakis \& Pharmakides, 2000). Among the other causes of anemia, heavy blood loss because of menstruation or parasitic infections can lower blood hemoglobin (Hgb) concentration. Acute and chronic infections, including malaria and HIV can also lower blood Hgb concentration. The presence of other micronutrient deficiencies can also increase the risk of anemia. Furthermore, the impact of haemoglobinopathies on anemia prevalence needs to be considered within some populations (WHO, 2001).

Anemia is also considered as an indicator of both poor nutrition and health status. The most dramatic health effects of anemia, increased risk of maternal and child mortality due to severe anemia, have been well documented (WHO, 2001; Aimakhu \& Olayemi, 2003 and Anorlu,et al. 2001). Patients with anemia have similar clinical symptoms irrespective of the cause. Fatigue, breathlessness, dizziness and headache are some of the common complaints. Examination of a stained blood smear using a microscope for morphology of red blood cell is helpful in diagnosing anemia in areas where automated analysis is less accessible (Bruno, et.al, 2006). Packed cell volume (PCV) of less than $33.0 \%$ is regarded as anemic by World Health Organization (WHO) (Aimakhu \& Olayemi, 2003).

\section{Prevalence of anemia among pregnant women attending antenatal clinic}

Anemia in pregnancy is a major public health problem, especially in developing countries. It affects $41.8 \%$ of pregnant women globally, with the highest prevalence in Africa (57.1\%) which corresponds to 17.2 million (Benoist, 2008). Different studies have shown different prevalence of anemia during pregnancy ranging from 16.6-95.0\% (Benoist, 2008).

A research finding published by World Health organization reveals that the prevalence of anemia among pregnant women in developing countries averages 56\% (ranging between 35 to $100 \%$ ). Identifying the associated factors which are responsible for the development of anemia during pregnancy would be of great help in mitigating the burden to some extent. Objective of the study was to find out the pattern of anemia and associated risk factors for anemia during pregnancy.

The prevalence of anemia in pregnancy in developing countries, reportedly still high. Nearly half of the pregnant women in the world are estimated to be anemic, with which $52 \%$ compared to $23 \%$ in industrialized countries (WHO, 2001). Recent world health organisation (WHO) data shows that approximately 10.8 million in African countries, 9.7 million in the Western Pacific and 24.8 million pregnant women in South East Asia are anemic and the highest number being in South East Asia (WHO, 2001). 
Subsequently, the World Health Organisation (2001) also reported that nearly 40\% of World population having anemia. The prevalence may be as high as 56-61\% in developing countries. The WHO estimated that more than half of pregnant women in the world have haemoglobin level of $<11.0 \mathrm{~g} / \mathrm{dl}$ which is indicative of anemia (1994). Higher incidence and severity have been reported especially in malaria endemic area. This is especially a major concern because Somalia is a malaria endemic area.

\section{FACTORS ASSOCIATED WITH ANEMIA}

Pregnant women in developing countries are at risk of anaemia due to poverty, grandmultiparity, too early pregnancies, too many and too frequent pregnancies spacing of $<1$ year, low socioeconomic status, illiteracy, and late booking of pregnant women at antenatal care units (WHO,2003). Mainly due to the above factors, the prevalence rates of anaemia were $65 \%$ in Kenya, 46\% in Ghana 42\% in Namibia 28\% in Tanzania and 45.5\% in Somalia (WHO, 2006). Furthermore, other risk factors are parasitic infestations, season, geographical location, food habits, gestational age, parity and pregnancies at early age (WHO, 2003).

All pregnant women receive routine daily supplementation of elemental iron and folic acid. Protection against malaria is usually achieved through the use of insecticide treated bed nets, intermittent preventive treatment of asymptomatic pregnant women, and early diagnosis and prompt and effective case management of malaria. Other interventions Include HIV screening and management, health education on diet, cooking, and early diagnosis and treatment of anaemia which depends on the severity and its cause as well as the gestational age of the patient. Correction of anaemia in pregnancy can be achieved either with haematinics or by blood transfusion (WHO, 2003).

A key component of a safe motherhood initiative is to reduce maternal mortality by half through the eradication of anaemia during pregnancy (Hogue, et al., 2007). The management of anaemia in pregnancy is a potentially feasible and cost-effective intervention to reduce maternal, foetal, and perinatal mortality and morbidity. However, the actual prevalence rates of pregnancy related conditions for many individual countries and communities are not known. Thus, it was recommended at the African regional consultation on the control of anaemia in pregnancy of the WHO that simple studies of prevalence and aetiology should be undertaken (Hogue, et al , 2007, \& Hogue, et al , 2006).

Many of the predisposing factors to anaemia in pregnancy are controllable and may lead to women becoming pregnant with anaemia; thus there is need for basic prevalence statistics to create awareness on the magnitude of anaemia in pregnancy in our environment and also to formulate strategies to reduce its adverse health consequences in order to improve maternal health and reduce poor perinatal outcome. Information on the prevalence would also be useful for the managers of health institutions and for district, provincial, and national maternal, child, and women's health programme development (Hogue, et al., 2007, \& Hogue, et al., 2006).

The causes of anaemia in the general population are generally same for anaemia in pregnancy. The causes of anaemia in pregnancy are often multifactorial. In developing countries, the major causes of anaemia in pregnancy are nutritional deficiencies, infections and infestations, haemorrhage and haemoglobinathies. Anaemia is also seen also in some chronic medical disorders like renal and hepatic diseases.

\section{Nutrition}

In many regions of the world nutritional deficiency is the major cause of anaemia in pregnancy. The World health Organization (WHO) estimates that about half of all pregnant women 
globally suffer from nutritional anaemia. Nutritional anaemia is mainly due iron and folate deficiency in diet. Diseases that cause poor dietary intake or malabsorption of these nutrients will also result in nutritional anaemia (WHO, 2002). Iron deficiency is the commonest cause of nutritional anaemia in both developing and industrialized countries and is usually as a result of poor diet. Sources of iron include meat (liver in particular) vegetables and dairy products. The demand for iron increases in pregnancy as it is required by both mother and fetus for growth and development. In developing countries the already depleted iron stores as a result of poor diet, too early, too many and too frequent pregnancies are unable to cope with the requirement of $1000 \mathrm{mg}$ of iron required during a normal pregnancy. The resultant effect is iron deficiency anaemia (Anorlu, 2006).

\section{Infections}

Pregnant women are more prone to infections as a result of depressed immunity. Anaemia due to infections is usually as a result of products from the infecting organisms causing ill health, fever, red cell destruction and/ or reduced red cell production. Bacterial infections used to be a leading cause of anaemia, however in the tropics and developing countries, malaria and more recently, HIV/AIDS are leading contributors to anaemia in pregnancy (WHO, 2001).

Malaria infection is a leading cause of anemia in the tropics both in pregnant and nonpregnant individuals. Malaria induced anaemia is more profound in pregnancy as the susceptibility to malaria is greater in the primigravidae. Anaemia resulting from malarial infection is caused by the destruction of infected and uninfected red blood cells as well as bone marrow suppression. Red blood cells infected with malaria parasites also accumulate and sequester in the placenta.

Anaemia is the most common haematological complication of the Human Immunodeficiency Virus (HIV) infection and may be consequent upon the effects of the virus itself or treatment with various drugs. The mechanisms of HIV induced anaemia occur through three mechanisms of decreased red blood cell production, increased red cell destruction and ineffective production of red blood cells.

\section{Haemorrhage}

Acute blood loss as result of ectopic pregnancy, antepartum haemorrhage and abortions are common causes of anaemia in pregnancy. Chronic blood loss from worm infestations, gastrointestinal ulcers and hemorrhoids results in depletion of iron stores and ineffective erythropoesis (WHO, 2006).

\section{Antenatal care}

Antenatal care (ANC) is the care a woman receives throughout her pregnancy in order to ensure that both the mother and child remain healthy. A healthy diet and lifestyle during pregnancy is important for the development of a healthy baby and may have long-term beneficial effects on the health of the child. Almost $90 \%$ of maternal deaths occur in developing countries and over half a million women die each year due to pregnancy and childbirth related causes (WHO, 2005).

Proper ANC is one of the important ways in reducing maternal and child morbidity and mortality. Unfortunately, many women in developing countries do not receive such care. Understanding maternal knowledge and practices of the community regarding care during pregnancy and delivery are required for program implementation (WHO, 2005).

ANC indirectly saves the lives of mothers and babies by promoting and establishing good health before childbirth and the early postnatal period - the time periods of highest risk. ANC 
often presents the first contact opportunity for a woman to connect with health services, thus offering an entry point for integrated care, promoting healthy home practices, influencing careseeking behaviours, and linking women with pregnancy complications to a referral system. Women are more likely to give birth with a skilled attendant if they have had at least one ANC visit (WHO, 2005).

While research has demonstrated the benefits of ANC through improved health of mothers and babies, the exact components of ANC and what to do at what time have been matters of debate. In recent years, there has been a shift in thinking from the high risk approach to focused ANC. The high risk approach intended to classify pregnant women as "low risk" or "high risk" based on predetermined criteria and involved many ANC visits. This approach was hard to implement effectively since many women had at least one risk factor, and not all developed complications; at the same time, some low risk women did develop complications, particularly during childbirth. Focused or goal oriented ANC services provide specific evidence-based interventions for all women, carried out at certain critical times in the pregnancy (WHO, 2011).

\section{Number of ANC visits}

A recent multi-country randomized control trial led by the WHO and a systematic review showed that essential interventions can be provided over four visits at specified intervals, at least for healthy women with no underlying medical problems. The result of this review has prompted WHO to define a new model of ANC based on four goal-oriented visits (WHO, 2011). This model has been further defined by what is done in each visit, and is often called focused antenatal care. The optimum number of ANC visits for limited resource settings depends not only on effectiveness, but also on costs and other barriers to ANC access and supply. A recent study from southern Tanzania found that health workers spent an average of 46 minutes providing focused ANC to a first time client, and 36 minutes for a revisiting client. This was thirty minutes more on average than the current practice and poses challenges for service delivery (WHO, 2011).

\section{Education}

Maternal knowledge of anemia is important because of its potential to encourage women to take iron supplements during pregnancy and after childbirth, affecting the iron status of both the mother and the child. In a small study in southern Israel, the presence of anemia in infants and level of maternal knowledge were inversely related, with low knowledge of anemia leading to a 12-fold increase in prevalence of anemia in infants compared to women with higher levels of knowledge (Bilenko, et al., 2007).

Increased consumption of animal source foods is an additional health-related behavior that could be encouraged by maternal knowledge of anemia (Neumann, et al., 2002). Benefits of consuming animal source foods include dietary diversity, relatively higher bioavailable forms of micronutrients, and overall better maternal nutrition affecting both the mother and child during pregnancy and lactation (Neumann, et al., 1994).

\section{Study Site}

\section{METHODOLOGY}

The study was carried out at SOS Hospital. This is a public Hospital located in Heliwa District in Mogadishu. It has a 50 bed capacity. Majority of the patients are urban poor. SOS Hospital offers full range of comprehensive health services i.e. medical, surgical, pediatric, obstetrics and gynecology and basic emergency services. 


\section{Study Population}

The study population comprised of 403 pregnant women of reproductive age group, aged between 15-49 years on their first Antenatal visit at SOS Hospital during their current pregnancy. The choice of this population was suitable because the antenatal women haven't received any supplementation and they constituted the urban poor population.

\section{Study Design}

Cross-sectional study design was used. The aim was to determine the prevalence of anemia among pregnant women attending antenatal clinic at SOS Hospital, and the outcome would be whether or not anemia in pregnancy is a prevalent condition. This design enabled the description of antenatal women suffering from anemia as well as estimation of the disease burden.

\section{Study Instrument}

The study instrument was structured questionnaire which were both categorical and open ended. Questionnaire administered to the study participants who fulfill eligibility criteria. The hemoglobin level was measured to identify the anemia.

\section{Sample Size Determination}

Literature review done in Somalia and Africa as a whole shows that prevalence of anemia in pregnancy ranges between $35-70 \%$. For purposes of this study, prevalence of anemia in pregnancy was taken as an average of 35 and $70 \%$ thus $52.5 \%$.The formula shown below was be used to determine the sample size.

Fisher's formula for estimating means and proportions was used to determine the sample size.

$\mathrm{n}=$ minimum sample size

$$
=(1.96)^{2} \times \mathrm{p}(1-\mathrm{p}) / \mathrm{d} 2
$$

$\mathrm{p}=$ proportion in target population estimated to have certain characteristics in this case overall prevalence of anemia $=52.5 \%$ (WHO, 2011).

$\mathrm{d}=$ precision/reliability to determine $\mathrm{p}=5 \%$

Therefore; sample size of ANC mothers

$$
\mathrm{n}=(1.96)^{2}(0.525(1-0.525) / 0.052
$$

Thus $n=384+19(5 \%$ non-response rate $)=403$

\section{Data Collection}

SOS Hospital has a busy ANC clinic. Every day they have approximately 40 new clients and we managed to recruit an average of 32 per day for 6 days per week. The sample was collected in the first two weeks of October, 2016. The principal investigator was responsible for conducting all interviews with the help of research assistants.

\section{Inclusion and Exclusion Criteria Inclusion Criteria}

1. All pregnant women attending antenatal clinic for the first time at SOS Hospital during the study period (August-December 2016)

2. Willingness to participate in the study 


\section{Exclusion criteria}

1. History of micronutrient supplementation during current pregnancy

2. Clients too sick or those not willing to participate in the study

3. Those who were recently transfused

\section{Quality Assurance Procedures}

Pretesting of the pre-designed questionnaire guide was carried out at SOS Hospital Antenatal Clinic before actual data collection. The questionnaires were analyzed. Feedback obtained would inform the changes and adjustments that needed to be addressed before a final draft would be made for administration to the research participants. In order to avoid double recruitment, the participants' file numbers were entered in a register upon recruitment for serialization. This register was counter-checked on a regular basis for double entries and if so discovered, one of the questionnaires was withdrawn and discarded and the serialization rectified before recruitment is continued. The research assistants were qualified nurses involved in the daily management of patients. They have had one day training on the administration of the questionnaire and clinical examination to be carried out before data collection started.

\section{Data Management/Analysis}

The data collected were transferred from EpiData into a Microsoft excel and then analyzed using Stata software. Data were entered into basic frequency and data cleaning done to identify outliers.

The data was then presented in frequencies, cross tabulations and diagrams as necessary. Descriptive analyses include measures of central tendency like the mean, measures of variability like standard deviation and range and univariate analysis. Inferential analysis was also carried out using chi square.

\section{Ethical Considerations}

Ethical clearance for this research has been sought from SOS Hospital/BU Ethics and Research committee and individuals who were interviewed. Pregnant women and all participants were educated on the relevance of the study and included in the research based on their consent to participate.

\section{Informed consent}

This was an academic research being conducted by a student from Benadir University, School of Post-graduate Studies. The participants were requested to participate in the research by answering the questionnaire through the research assistants and blood test for $\mathrm{Hb}$. The respondent's participation was voluntary and had freedom to withdraw at any time if may feel so and there were no victimization for any withdrawal.

\section{Privacy and Confidentiality}

All information provided to the interviewers was kept confidential and records were securely stored in a locker. All information that respondents give was handled with security and confidentiality.

\section{Anonymity}

The participants name and identity were kept anonymous. Only their responses and findings were presented in the study. 


\section{RESULTS}

A total of four hundred and three pregnant women at different stages of pregnancy attending antenatal clinics at SOS Hospitals were randomly selected for the cross sectional study. Of the 403 selected women, $41(10.17 \%)$ were in their first trimester of their pregnancy, one hundred and seventy six (43.67\%) were in the second trimester, while $186(46.15 \%)$ were in the third or last trimester of their pregnancy.

\section{Socio-demographic characteristics}

In this study $403(100 \%)$ of the required sample pregnant women attending antenatal care were participated in the study. The mean age of the respondents was $23.8( \pm 5.1)$ years. Around $34 \%$ of respondent were in age group of $20-24$ years and about $5.46 \%$ were in age group of 35 -and above years. Majority of the women interviewed were married $(95.53 \%)$ and urban dwellers (96.53\%). About (48.14\%) of the respondents were unable to read and write, (25.81\%) can read and write, (13.40\%) had primary school level and (7.94\%) had secondary school level, the percentage of pregnant women who had college and university level were (4.71\%). Regarding occupation majority of the respondent were house wives (94.04). (Table 1)

Table 5.1: Socio-demographic and economic characteristics of respondent of pregnant women

\begin{tabular}{|l|l|l|l|}
\hline Variable & Frequency (\%) & Variable & Frequency (\%) \\
\hline Age & & Marital Status & \\
$15-19$ & $92(22.83)$ & Married & $385(95.53)$ \\
$20-24$ & $137(34.00)$ & Divorced & $18(4.47)$ \\
$25-29$ & $114(28.29)$ & Residence & \\
$30-34$ & $38(9.43)$ & Urban & $389(96.53)$ \\
35 and above & $22(5.46)$ & Rural & $14(3.47)$ \\
Mothers' level of Edu. & & Mothers' occupation & \\
Illiterate & $194(48.14)$ & Housewife & $379(94.04)$ \\
Literate & $104(25.81)$ & Government Employee & $2(0.50)$ \\
Primary & $54(13.40)$ & Private Employee & $9(2.23)$ \\
Secondary & $32(7.94)$ & Merchant & $11(2.73)$ \\
University/college & $19(4.71)$ & Farmer & $2(0.50)$ \\
Husbands' level of Edu. & & Husbands' occupation & \\
Illiterate & $60(14.89)$ & Farmer & $15(3.72)$ \\
Literate & $159(39.45)$ & Government employee & $9(2.23)$ \\
Primary & $24(5.96)$ & Private employee & $213(52.85)$ \\
Secondary & $72(17.87)$ & Daily Laborer & $56(13.90)$ \\
University/College & $88(21.84)$ & Merchant & $76(18.86)$ \\
& & Other & $34(8.44)$ \\
\hline
\end{tabular}

\section{Pregnancy and Obstetric related characteristic of respondents}

Most of the respondents had less than three times ANC visit. Around twenty-five point eightyone (25.81\%) percent of the respondents have history of abortion and $7.20 \%$ have history of still birth. Among the respondents 3.47\% have started ANC while their pregnancy is less than 12 weeks gestation, $50.37 \%$ have started ANC while their pregnancy is between $12-24$ weeks of gestation and $46.15 \%$ have started after 24 week of gestation (Table 2). 
Table 5.2: Distribution of obstetric and pregnancy related factors

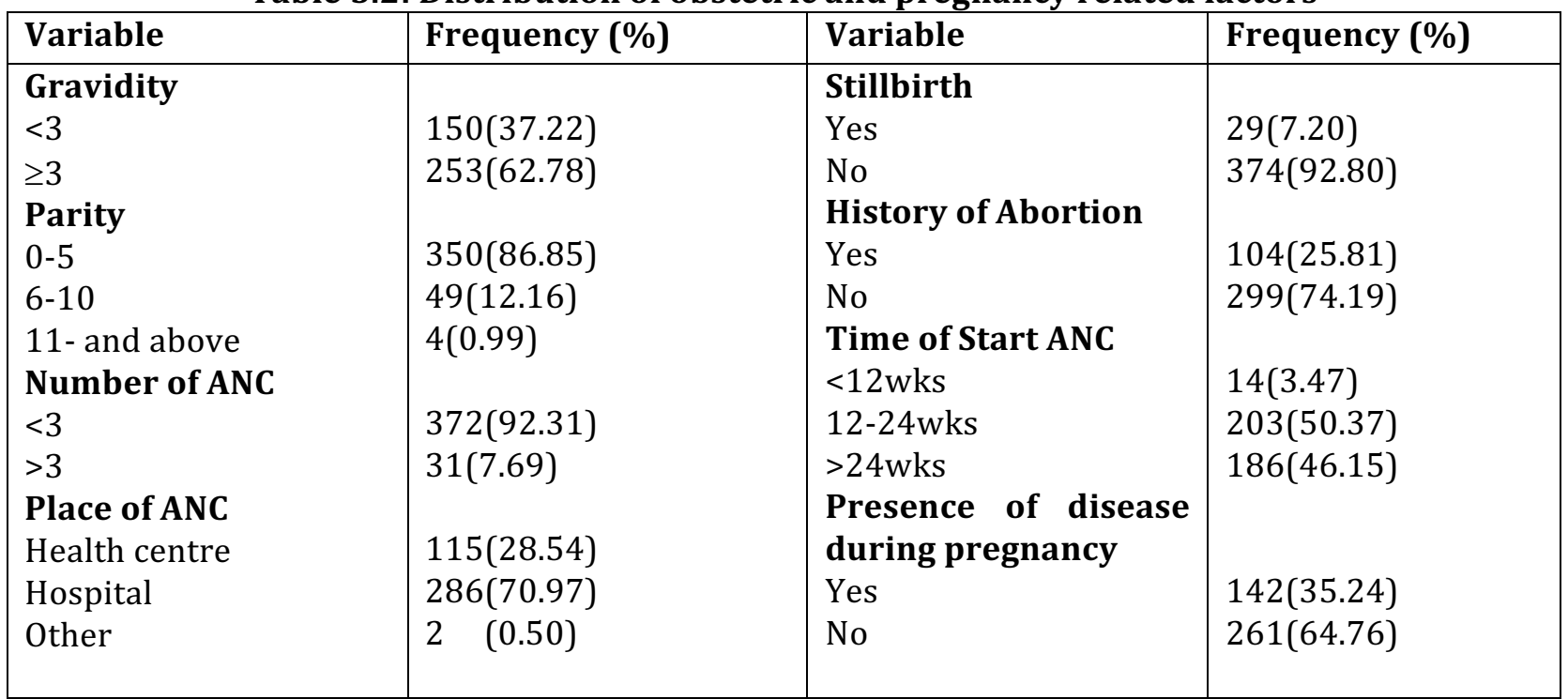

\section{Prevalence of anemia}

This study targeted pregnant women. The results in Table 3 showed that the prevalence of mild anemia was $15.14 \%$, moderate anemia $56.58 \%$ and severe anemia was $12.66 \%$. The prevalence of anemia was higher in the age groups 20-24 years compared to the rest of the age groups.

Table 5.3 Prevalence of anemia in pregnant women by levels

\begin{tabular}{|l|l|l|}
\hline Levels & No & n (\%) \\
\hline Mild & 61 & 15.14 \\
Moderate & 228 & 56.58 \\
Severe & 51 & 12.66 \\
\hline
\end{tabular}

The study has revealed that anemia was more prevalent (97.4\%) in the age group of 30-34. Other age groups 15-19, 20-24, 25-29, and >35 with 82.6, 83.2, 85.1, and 72.7 respectively as shown in table 5.4 .

Table 5.4 Prevalence of anemia in pregnant women by age group

\begin{tabular}{|l|l|l|}
\hline Characteristics & \multicolumn{2}{|c|}{ No Anemia } \\
& \multicolumn{1}{|c|}{ n (\%) } \\
\hline Age & 92 & $76(82.6)$ \\
$15-19$ & 137 & $114(83.2)$ \\
$20-24$ & 114 & $97(85.1)$ \\
$25-29$ & 38 & $37(97.4)$ \\
$30-34$ & 22 & $16(72.7)$ \\
35 and above & \multicolumn{2}{|c}{} \\
\hline
\end{tabular}




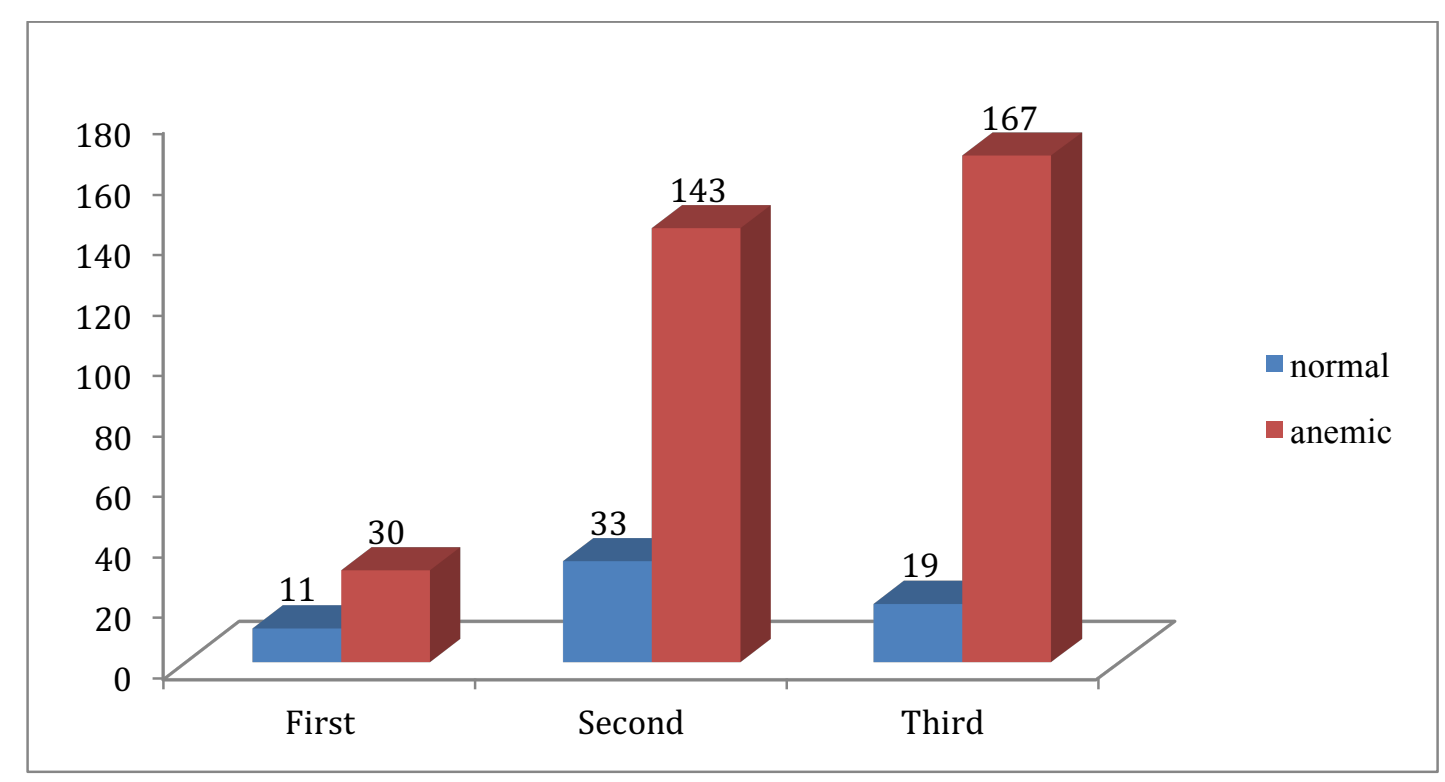

Fig. 5.1: Levels of Anemia at different trimesters of the pregnant mothers

Figure 5.1 above shows that majority of anemia cases occur in the third trimester 167 , second trimester 143 and first trimester 30 respectively.

\section{ASSOCIATION BETWEEN SOCIO-DEMOGRAPHIC FACTORS WITH ANEMIA}

The results in Table 7 show that age of the pregnant women and family size were found to be significant. Pregnant women at age of 25--29 were less likely to be anemic compared to those pregnant women at the age of $20-24$ (OR 0.75, 95\%CI $0.37-0.87$ ). Family size of pregnant women was found to be associated with anemia. Pregnant women whose family size were greater than 13 and more were more likely to be anaemic compared to those whose family size was less than 12 (OR 8.41, 95\%CI 1.33-52.92). 
Table 5.6: Socio- demographic factors associated with Anemia

Anaemia

\begin{tabular}{|c|c|c|c|c|}
\hline Variable & $\mathbf{N}$ & n (\%) & OR & 95\% (CI) \\
\hline Age Bracket & & & & \\
\hline $15-19$ & 92 & $76(82.6)$ & 1.0 & \\
\hline $20-24$ & 137 & $114(83.2)$ & 0.95 & $0.47-1.93$ \\
\hline $25-29$ & 114 & $97(85.0)$ & 0.63 & $0.29-0.95^{*}$ \\
\hline $30-34$ & 38 & $37(97.3)$ & 0.12 & $0.01-2.65$ \\
\hline 35 and above & 22 & $16(72.7)$ & 1.78 & $0.72-5.30$ \\
\hline Residence & & & & \\
\hline Rural & 14 & $13(92.8)$ & 1.0 & \\
\hline Urban & 389 & $327(84.0)$ & 2.46 & $0.31-19.2$ \\
\hline Family Size & & & & \\
\hline $1-6$ & 324 & $275(84.8)$ & 1.0 & \\
\hline $7-12$ & 74 & $63(85.1)$ & 0.97 & $0.48-1.9$ \\
\hline 13 and above & 5 & $2(40.0)$ & 8.41 & $1.33-52.92^{*}$ \\
\hline Income Class & & & & \\
\hline Class One & 394 & $333(84.5)$ & 1.0 & \\
\hline Class Two & 9 & $7(77.8)$ & 1.55 & $0.31-7.70$ \\
\hline Mothers' educational & & & & \\
\hline level & 194 & $170(87.6)$ & 1.0 & \\
\hline Illiterate & 104 & $88(84.6)$ & 1.28 & $0.64-2.55$ \\
\hline Literate & 54 & $41(75.9)$ & 2.24 & $1.04-4.82^{*}$ \\
\hline Primary & 32 & $25(78.1)$ & 1.98 & $0.76-5.11$ \\
\hline Secondary & 19 & $16(84.2)$ & 1.32 & $0.35-4.91$ \\
\hline University/College & & & & \\
\hline Parity & 350 & $296(84.5)$ & 1.0 & \\
\hline $0-5$ & 49 & $42(85.7)$ & 0.91 & $0.38-2.14$ \\
\hline $6-10$ & 4 & $2(50)$ & 5.48 & $2.74-10.26^{*}$ \\
\hline 11 and above & & & & \\
\hline Number of ANC & 372 & $313(84.1)$ & 1.0 & \\
\hline$<3$ & 31 & $27(87.0)$ & 0.78 & $0.26-0.98^{*}$ \\
\hline$>3$ & & & & \\
\hline Trimesters & & & & \\
\hline First trimester & 41 & $30(73.2)$ & 1.0 & $(1.23-2.45)$ \\
\hline Second trimester & 176 & $143(81.3)$ & 1.83 & $(2.03-4.25)^{*}$ \\
\hline Third trimester & 186 & $167(89.8)$ & 3.63 & \\
\hline Knowledge on Anemia & & & & \\
\hline Yes & 392 & $339(86.50)$ & 1.0 & $0.06-3.04$ \\
\hline No & 10 & $9(90.0)$ & 1.02 & \\
\hline
\end{tabular}

*= significant where $\mathrm{P}$-value $<0.05, \mathrm{OR}=$ Odds ratio, $\mathrm{CI}=$ Confidence interval

\section{DISCUSION}

\section{Socioeconomic and Demographic Characteristics}

In this study $403(100 \%)$ of the required sample pregnant women attending antenatal care were participated in the study. The mean age of the respondents was $23.8( \pm 5.1)$ years. Around $34 \%$ of respondent were in age group of 20-24 years and about $5.46 \%$ were in age group of 35 -and above years. Majority of the women interviewed were married $(95.53 \%)$ and urban dwellers (96.53\%). About (48.14\%) of the respondents were unable to read and write, (25.81\%) can read and write, (13.40\%) had primary school level and (7.94\%) had secondary school level, the percentage of pregnant women who had college and university level were 
(4.71\%). Regarding occupation majority of the respondents were house wives (94.04). Majority of the mothers were married (95.5\%). The average family size was 4.7 .

\section{Prevalence of Anemia and its severity}

More than two-thirds (84.3\%) of the pregnant women studied were anemic. This finding is much higher than the national prevalence of anemia in pregnant women, which is $45.5 \%$ (World Bank, 2016). This figure is higher than the prevalence of anemia in pregnant women of some other developing countries such as India and Pakistan (Makhoul etal, 2012). This discrepancy could be due to the sociocultural issues of the respondents and the time gap between the current study and the other studies conducted before.

The prevalence of anaemia was 84.3 per cent among pregnant women (340 out of 400$)$. Out of 340, 61(15.14 \%) had mild anaemia (hb10 to $10.99 \mathrm{gm} / \mathrm{dl}), 228$ (56.5\%) had moderate anaemia (hb 7 to $9.9 \mathrm{gm} / \mathrm{dl})$ and $51(12.7 \%)$ had severe anaemia $(\mathrm{hb}<7 \mathrm{gm} / \mathrm{dl})$.

The prevalence of anaemia was 97.4 per cent among ante-natal women who were in the age group of 30-34 years followed by the age group of 25-29 (85.1\%) 15-19 with prevalence of $(82.6 \%)$ and 35 and above (72.7\%).

The study revealed an unacceptably high level of prevalence of Anemia at $84.3 \%$ among pregnant women attending at SOS Hospital in Mogadishu. The present study indicates that the prevalence of anaemia $(\mathrm{Hb}<11.0 \mathrm{~g} \mathrm{dl})$ among pregnant women attending $\mathrm{MCH} \&$ OPD departments in SOS Hospital was $84.3 \%$ indicating that anemia (IDA) remains a major health problem in these communities.

The study findings indicate a high increment in the prevalence of anemia compared to those reported in previous studies conducted by World Bank report, 2016 which indicates that national prevalence of anemia in pregnancy was 45.5\% (World Bank, 2011).

\section{Associated factors with Anemia}

The mean number of pregnancies, and number of deliveries, were (3.90) and (2.64), respectively. About 186 (46.1\%) of the mothers were in their third trimester, 176 (43.6\%) were in the second trimester, and the remaining $41(10.1 \%)$ were in the first trimester.

The study shows that parity and age of current pregnancy (trimester) were important variables, which have shown a significant association with anemia in the current study. The risk of developing anemia increases with the age of pregnancy (trimester).The risk of developing anemia was higher in third and second trimester when compared with those in the first trimester.

This finding is consistent with a study done in Saudi Arabia, which found that the prevalence of anemia is higher in the third trimester in comparison with first trimester (Haidar, 2010), and another study conducted in India, which also indicated that the prevalence of anemia was higher in pregnant women in the third and second trimesters (Vivak etal, 2012). Additionally, studies conducted in Malaysia, Vietnam, and Nepal found that increased gestational age is significantly associated with the risk of developing anemia (Makhoul etal, 2012). This could be due to the fact that when the gestational age increases the mother becomes weak and the iron in the blood is shared with the fetus in the womb therefore decreasing the iron binding capacity of the mother's blood. 
The other important variable significantly associated with anemia is number of deliveries (parity). Mothers who delivered more than 11 were five times more likely to became anemic than those delivered less than 11. This finding is consistent with studies conducted in Saudi Arabia and India, which found that increased number of deliveries is positively associated with the risk of developing anemia (Viva ketal, 2012). This could be due to the loss of iron and other nutrients during increased and repeated pregnancies and also the possibility of sharing of resources with the fetus. However, other studies conducted in Ethiopia and Nepal did not find association between parity and anemia (Makhoul etal, 2012). This could be due to the difference in sociocultural characteristics of the study populations.

The study also shows that the mothers who visit ANC more than three times were less likely to become anemic than those with visits less than three times.

The other variables with significant association with anemia were iron supplementation during pregnancy. The risk of developing anemia increased in pregnant women who did not receive iron supplementation during pregnancy when compared with those who received iron supplementation. This finding is consistent with the findings from studies in Vietnam and India, which indicated that lack of iron supplementation is among the most significant risk factors for developing anemia during pregnancy (Aikawa, Sasaki and Binna, 2006).

\section{Socio- demographic factors associated with Anemia}

The study has shown that age of the pregnant women and family size were found to be significant. Pregnant women at age of 25--29 were less likely to be anemic compared to those pregnant women at the age of 20-24 (OR 0.75, 95\%CI $0.37-0.87$ ). Family size of pregnant women was found to be associated with anemia. Pregnant women whose family size were greater than 13 and more were more likely to be anaemic compared to those whose family size was less than 12 (OR 8.41, 95\%CI 1.33-52.92).

\section{Prevalence of Anemia and its severity}

The study revealed an unacceptably high level of prevalence of Anemia at $84.3 \%$ among pregnant women attending at SOS Hospital in Mogadishu. The present study indicates that the prevalence of anaemia $(\mathrm{Hb}<11.0 \mathrm{~g} \mathrm{dl})$ among pregnant women attending MCH \& OPD departments in SOS Hospital was $84.3 \%$ indicating that anemia (IDA) remains a major health problem in these communities.

More than two-thirds (84.3\%) of the pregnant women studied were anemic. This finding is much higher than the national prevalence of anemia in pregnant women, which is $45.5 \%$ (World Bank, 2016). The prevalence of anaemia was 84.3 per cent among pregnant women (340 out of 400 ). Out of $340,61(15.14 \%$ ) had mild anaemia (hb10 to $10.99 \mathrm{gm} / \mathrm{dl}$ ), 228 $(56.5 \%)$ had moderate anaemia (hb 7 to $9.9 \mathrm{gm} / \mathrm{dl})$ and $51(12.7 \%)$ had severe anaemia (hb < $7 \mathrm{gm} / \mathrm{dl})$.

\section{Associated factors with Anemia}

The number of pregnancies, and number of deliveries, were (3.90) and (2.64), respectively. About $186(46.1 \%)$ of the mothers were in their third trimester, 176 (43.6\%) were in the second trimester, and the remaining 41 (10.1\%) were in the first trimester.

The study shows that parity and age of current pregnancy (trimester) were important variables, which have shown a significant association with anemia in the current study. The risk of developing anemia increases with the age of pregnancy (trimester).The risk of 
developing anemia was higher in third and second trimester when compared with those in the first trimester.

\section{For Community leaders}

\section{RECOMMENDATION}

- Increase awareness of the pregnant women about importance of Antenatal care and Iron/folate supplementation during pregnancy. Routine iron supplementation should be encouraged as a prophylactic measure.

- Educating women on early initiation and compliance would be beneficial in reducing the burden of the disease.

\section{For SOS Hospital, Ministry of Health and Other Health Partners}

- Should ensure continuous and timely supply of Iron and folate supplementation

- Should conduct training courses on anemia and benefits of IFA (Iron/Folate Acid) during pregnancy for health personnel working in ANC

- Sensitization of the community about anemia and Iron and folate supplement during pregnancy through health Education.

- Outreach services to enhance access of supplements

- Engaging the extension health workers in distribution of the supplements

- There is need for more stringent measures in investigating and screening of pregnant women for anemia by taking blood samples for full haemogram.

- Corrective measures should then be instituted immediately.

\section{Researcher and scientific community}

- Further research should be carried out on determinant factors of anemia during pregnancy to strengthen and broaden these findings and obtain data base for effective planning and implementation of control programmes.

\section{References}

Agan, T. , Ekabua, J. E. Udoh, A. E. Ekanem, E. I., Efiok, E. and M. A. Mgbekem (2010). "Prevalence of anemia in women with asymptomatic malaria parasitemia at first antenatal care visit at the University of Calabar Teaching Hospital, Calabar, Nigeria," International Journal of Women's Health, vol. 2, no. 1, pp. 229-233.

Aimakhu CO, Olayemi O. (2003). Maternal haematocrit and pregnancy outcome in Nigerian women. West Afr J Med; 22:18-21.

Akhtar, M. and Hassan, I. (2012). "Severe Anemia during late pregnancy," Case Reports in Obstetrics and Gynecology, vol. 2012, Article ID 485452, 3 pages,.

Anorlu RI, Odum CU, Essien EE. Asymptomatic malaria parasitaemia in pregnant women at booking in a primary health care facility in a periurban community in Lagos, Nigeria. Afr J Med Sci 2001; 30:39-41.

Anorlu, R. I.,Oluwole, A. A. and Abudu , 0.(2006). "Sociodemographic factors in anaemia in pregnancy at booking in Lagos, Nigeria,” Journal of Obstetrics and Gynaecology, vol. 26, no. 8, pp. 773-776.

Baig-Ansari, N., Badruddin, S. H. and Karmaliani, R. et al. (2008). “Anemia prevalence and risk factors in pregnant women in an urban area of Pakistan," Food and Nutrition Bulletin, vol. 29, no. 2, pp. 132-139.

Baig-Ansari, S. H. Badruddin, R. Karmaliani et al., "Anemia prevalence and risk factors in pregnant women in an urban area of Pakistan," Food and Nutrition Bulletin, vol. 29, no. 2, pp. 132- 139, 2008.

Baker, S. J. and DeMaeyer, E. M. (1979). "Nutritional anemia: Its understanding and control with special reference to the work of the world health organization," American Journal of Clinical Nutrition, vol. 32, no. 2, pp. 368-417,

Balarajan,Y, Ramakrishnan, U. ,Ozaltin, E. Shankar, A. H and S. V. Subramanian(2011). "Anaemia in low-income and middle-income countries," The Lancet, vol. 378, no. 9809, pp. 2123-2135.

Benoist B, McLean E, Cogswell M, Egli I, Wojdyla D. (2008).Worldwide prevalence of anemia, WHO Vitamin and Mineral Nutrition Information System, 1993-2005. Public Health Nutr,Geneva; 12(4): 444-454. 
Bilenko N, Yehiel M, Inbar Y, et al.( 2007).The association between anemia in infants, and maternal knowledge and adherence to iron supplementation in southern Israel. Isr Med Assoc J; 9:521-524. [PubMed: 17710783]

Brooker, S., Hotez, P. J. and Bundy D.A. P (2008). "Hookworm-related anaemia among pregnant women: a systematic review," PLoS Neglected Tropical Diseases, vol. 2, no. 9, article e291.

Bruno B, Erin M, Mary C. (2006).WHO Global Database on Anemia Worldwide prevalence of anemia 1993-2005. WHO, Geneva.

Centers for disease control and prevention (1998). Recommendation to prevent and control iron deficiency in the United States. MMWR Morb Mortal Wkly Rep;47:1-36

DeMaeyer E, Adiels-Tegman M. (1985). The prevalence of anemia in the world. World Health Stat;38:302-316

Esmat, B., Mohammad, R and. Behnam, S. et al., (2010). "Prevalence of iron deficiency anemia among iranian pregnant women; a systematic review and meta-analysis," Journal of Reproduction and Infertility, vol. 11, no. 1, pp. 17-24.

Gautam VP, Bansal YY, Taneja DK, Saha R. (2002). Prevalence of anemia amongst pregnant women and its sociodemographic associates in a rural area of Delhi. Indian J Community Med; 27(4):157-60.

Haidar, J "Prevalence of anaemia, deficiencies of iron and folic acid and their determinants in ethiopian women," Journal of Health, Population and Nutrition, vol. 28, no. 4, pp. 359-368, 2010.

Haidar, J. (2010). "Prevalence of anaemia, deficiencies of iron and folic acid and their determinants in ethiopian women," Journal of Health, Population and Nutrition, vol. 28, no. 4, pp. 359-368,.

Hercberg S, Galan P (1992). Nutritional anemias. Baillieres Clin Haematol; 5: 143-168.

Hogue, A. K. M., Kadar, S. B., Hogue, E. and C. Mugero (2006). "Prevalence of anaemia in pregnancy at Greytown, South Africa," Tropical Journal of Obstetrics and Gynaecology, vol. 23, no. 1, pp. 3-7.

Hogue, M., Kader, S. B. and E.Hogue (2007). "Prevalence of anaemia in pregnancy in the Uthungulu health district of KwaZulu-Natal, South Africa," South African Family Practice, vol. 49, no. 6, p. 16.

Makhoul, D. Taren, B. and Duncan et al.,( 2012) "Risk factors associated with anemia, iron deficiency and iron deficiency anemia in rural Nepali pregnant women," Southeast Asian Journal of Tropical Medicine and Public Health, vol. 43, no. 3, pp. 735-745.

Neumann CG, Harris DM, Rogers LM.( 2002). Contribution of animal source foods in improving diet quality and function in children in the developing world. Nutr Res; 22:193-220.

Neumann, CG. and Harrison G. (1994). Onset and evolution of stunting in infants and children. Examples from the Human Nutrition Collaborative Research Support Program, Kenya and Egypt studies. Eur J Clin Nutr. 48:S90S102. [PubMed: 8005095].

Baker SJ and DeMaeyer,E.M “Nutritional anemia: Its understanding and control with special reference to the work of the world health organization," American Journal of Clinical Nutrition, vol. 32, no. 2, pp. 368-417, 1979.

Salhan, S. Tripathi, V. Singh, R. and Gaikwad, H. S.(2012). "Evaluation of hematological parameters in partial exchange and packed cell transfusion in treatment of severe anemia in pregnancy," Anemia, vol. 2012, Article ID 608658, 7 pages.

Siamak N. Nabili. Anemia [online] [Cited 2014 January 30]. Available from: URL

Sifakis S, Pharmakides G. Anemia in pregnancy. Ann N YAcad Sci 2000; 900: 125-136.

Toteja,G. S., Singh,P. B., and Dhillon, S. et al. (2006). "Prevalence of anemia among pregnant women and adolescent girls in 16 districts of India," Food and Nutrition Bulletin, vol. 27, no. 4, pp. 311-315

Vivek, A. B. Halappanavar, P. R. Vivek, S. B. Halki, V. S. Maled, and P. S. Deshpande, "Prevalence of Anemia and its epidemiological," Determinants in Pregnant Women, vol. 5, no.3, pp. 216-223, 2012.

WHO (1989).Preventing and Controlling Iron Deficiency Anemia through Primary Health Care. Geneva. WHO.

WHO (2001).Iron Deficiency Anemia: Assessment Prevention and Control. WHO, Geneva,.

WHO (2002).The World Health Report 2002: Reducing risks, promoting healthy life. WHO, Geneva.

WHO (2003).Controlling disease due to helminthes infections. WHO, Geneva.

WHO (2006).Roll Back Malaria Department Guidelines for the treatment of malaria. WHO, Geneva. 
Dahie, H. A., \& Heyle, A. A. (2017). Prevalence of Anemia and Its Associated Factors Among Pregnant Women Attending Antenatal Clinic At SOS Hospital In Heliwa District, Mogadishu. Advances in Social Sciences Research Journal, 4(15) 183-200.

WHO/CDC (2008). Worldwide Prevalence of Anemia 1993-2005: WHO Global Database on Anemia, WHO Press, Geneva, Switzerland.

World Bank (2004). Public health at a glance. December.

World Bank (2016).Health Nutrition and Population Statistics. World Bank.

World Health Organisation (2011). Vitamin and Mineral Nutrition/ Anaemia. WHO.

World Health Organisation(2005). Worldwide prevalence of anaemia 1993-2005: WHO global database on anaemia.

World Health Organization (1992). The prevalence of anaemia in women: a tabulation of available information, 2nd Ed., Geneva: WHO.

World Health Organization (2002).World Health Report. Reducing Risk, Promoting Healthy Life. Geneva: WHO.

World Health Organization (2005). Global Database on Iron Deficiency and Anaemia, Micronutrient Deficiency Information System. . Geneva: World Health Organisation.

World Health Organization (2011). Global Health Observatory (GHO)/HIV. 